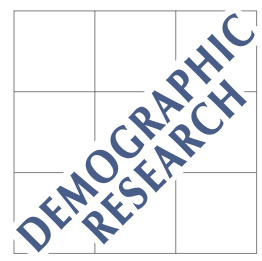

Demographic Research a free, expedited, online journal of peer-reviewed research and commentary in the population sciences published by the Max Planck Institute for Demographic Research Konrad-Zuse Str. 1, D-18057 Rostock · GERMANY www.demographic-research.org

DEMOGRAPHIC RESEARCH

VOLUME 24, ARTICLE 4, PAGES 113-144 PUBLISHED 28 JANUARY 2011

http://www.demographic-research.org/Volumes/Vol24/4/

DOI: 10.4054/DemRes.2011.24.4

Research Article

\title{
The crossover between life expectancies at birth and at age one: The imbalance in the life table
}

\section{Vladimir Canudas-Romo}

\section{Stan Becker}

(c) 2011 Vladimir Canudas-Romo \& Stan Becker.

This open-access work is published under the terms of the Creative Commons Attribution NonCommercial License 2.0 Germany, which permits use, reproduction \& distribution in any medium for non-commercial purposes, provided the original author(s) and source are given credit. See http://creativecommons.org/licenses/by-nc/2.0/de/ 


\section{Table of Contents}

$1 \quad$ Introduction $\quad 114$

2 Data 116

3 Methods 118

3.1 The crossing in life expectancies 118

$\begin{array}{ll}3.2 & \text { The difference in life expectancies and its components } \\ \end{array}$

$4 \quad$ Results 122

4.1 The crossover in industrialized countries 122

4.2 The crossover in countries of the world 129

4.3 The imbalance in the life tables for the black and white populations of the USA 130

5 Discussion 132

$\begin{array}{ll}\text { References } & 136\end{array}$

$\begin{array}{ll}\text { Appendix } & 141\end{array}$ 


\title{
The crossover between life expectancies at birth and at age one: The imbalance in the life table
}

\author{
Vladimir Canudas-Romo ${ }^{1}$ \\ Stan Becker $^{2}$
}

\begin{abstract}
The single most used demographic measure to describe population health is life expectancy at birth, but life expectancies at ages other than zero are also used in the study of human longevity. Our intuition tells us that the longest life expectancy is that of a newborn. However, historically, the expectation of life at age one $\left(e_{1}\right)$ has exceeded the expectation of life at birth $\left(e_{0}\right)$. The crossover between $e_{0}$ and $e_{1}$ only occurred in the developed world in the second half of the twentieth century. Life tables for populations that have not achieved this crossing between life expectancy at birth and at age one are referred to here as imbalanced. This crossover occurs when infant mortality is equal to the inverse of life expectancy at age one. This simple relation between mortality at age zero and mortality after age one divides the world into countries that have achieved the crossover in life expectancies and those that have not. It is a within-population comparison of mortality at infancy and after age one. However, results of these within-population comparisons can be used for comparison between populations. For countries that have already achieved this crossing in life expectancies, the sex differential in the timing of the crossing is marked: Females attain the crossing before males for every single population and in some cases by up to 18 years earlier. However, for most developing countries, life expectancy at age one is still higher than life expectancy at birth, in some cases by several years. Subpopulation comparisons for the US show that black Americans are near to transitioning out of the imbalanced life table situation while the white population has already done so.
\end{abstract}

\footnotetext{
${ }^{1}$ Department of Biostatistics, University of Copenhagen, Denmark. Department of Population, Family and Reproductive Health, Johns Hopkins Bloomberg School of Public Health, Baltimore, USA. 615 N Wolfe Street, Room E4634, Baltimore MD 21205. Ph: (410) 955-8694, Fax: (410) 955-2303. E-mail: vcanudas@jhsph.edu.

${ }^{2}$ Department of Population, Family and Reproductive Health, Johns Hopkins Bloomberg School of Public Health, Baltimore, USA.
} 


\section{Introduction}

Since the 1920s and 1930s, the summary indicator most widely used to describe population health is life expectancy at birth, $e_{0}$ (Robine 2006; Dublin 1923; Dublin and Lotka 1934). Period life expectancy at birth is defined as the average number of years that a newborn would live given a set of death rates observed in a calendar year (Preston, Heuveline, and Guillot 2001). Changes in mortality in the first year of life strongly affect life expectancy at birth, and it has been suggested that the time series of $e_{0}$ alone is not well suited for studying the length of life in aging populations (Kannisto 2001). This could be circumvented if both infant mortality and life expectancy at age one are used as comparative measures of the level of mortality in a population (Kintner 2004). Infant mortality levels can be compared over time, or over subpopulations defined in terms of sex, race, nationality, education, social class, etc. (Frisbie et al. 2004; Martin et al. 2005; Hummer et al. 2007). Another comparison can be made by observing the relation between the level of infant mortality in a population and its mortality at adult ages (Finch and Crimmins 2004; Galobardes, Lynch, and Smith 2004). In this study we address an alternative comparison by analyzing the crossover between life expectancy at birth and at age one, which relates the information of infant mortality to mortality at other ages.

For high-income countries, the $e_{0}$ calculated from period life tables is currently higher than the life expectancy at any other age. In historical populations as well as in most developing countries, however, high rates of infant and early childhood mortality result in lower values of life expectancy at birth than at other ages. In such populations, those surviving the hazards of early childhood have a higher life expectancy than newborns and the highest life expectancy occurs not at birth but at a later age. Let an imbalance in a life table be defined as a situation where levels of life expectancy at a younger age $x, e_{x}$, are lower than at an older age $y, e_{y}$, this can be expressed as $e_{x}<e_{y}$ when $x<y$. Of particular interest is the case of an imbalance between life expectancy at birth $e_{0}$ and at age one $e_{1}$, with the latter having higher values, $e_{0}<e_{1}$. Here we show how the mathematical relations of the life table allow us to find the precise moment when this imbalance stops existing which relates life expectancies at birth and at age one, and infant mortality.

Studies of time trends in life expectancy generally focus on a fixed age, and little attention has been given to the relation to or imbalance between life expectancies at other ages. Oeppen and Vaupel (2002) concentrated on female life expectancy at birth in the specific countries holding the record value and its constant rate of increase since 1840 . White (2002) fitted straight lines to the time trend of $e_{0}$ in western industrialized countries during the second half of the 20th century. Vallin and Meslé (2009) revised Oeppen and Vaupel's findings describing the series of $e_{0}$ as multiple segments that correspond to phases of the epidemiological transition (Omran 1971). While the timing, pace, and trajectories of demographic and epidemiologic transitions around the world vary widely 
(Riley 2005), across all countries initial increases in $e_{0}$ were mainly due to considerable reductions in early life mortality. Later and ongoing gains in life expectancy are the result of mortality declines at older ages (Horiuchi 1991; Kannisto et al. 1994; Wilmoth 2000). However, life expectancy at birth alone cannot distinguish these changing stages of mortality reductions.

In the second half of the twentieth century in developed countries, life expectancy by age became a monotonic decreasing function with increasing age. However, in the past this was not the case. Figure 1 presents life expectancy by age at different times for the population of the Netherlands. In 1850 life expectancy at birth was only higher than life expectancies after age 21 . Over time this changed and by 1950 the only remaining life expectancy higher than $e_{0}$ was $e_{1}$. These substantial gaps between the life expectancy at birth and life expectancy at age one can be found in other countries (Canudas-Romo and Engelman 2009). The country comparisons of the timing of the crossing between $e_{0}$ and $e_{1}$, and the relations of the life table functions at the time of this crossing are the focus of this paper.

\section{Figure 1: $\quad$ Life expectancy by age for the total population of the Netherlands} in $1850,1900,1950$ and 2000

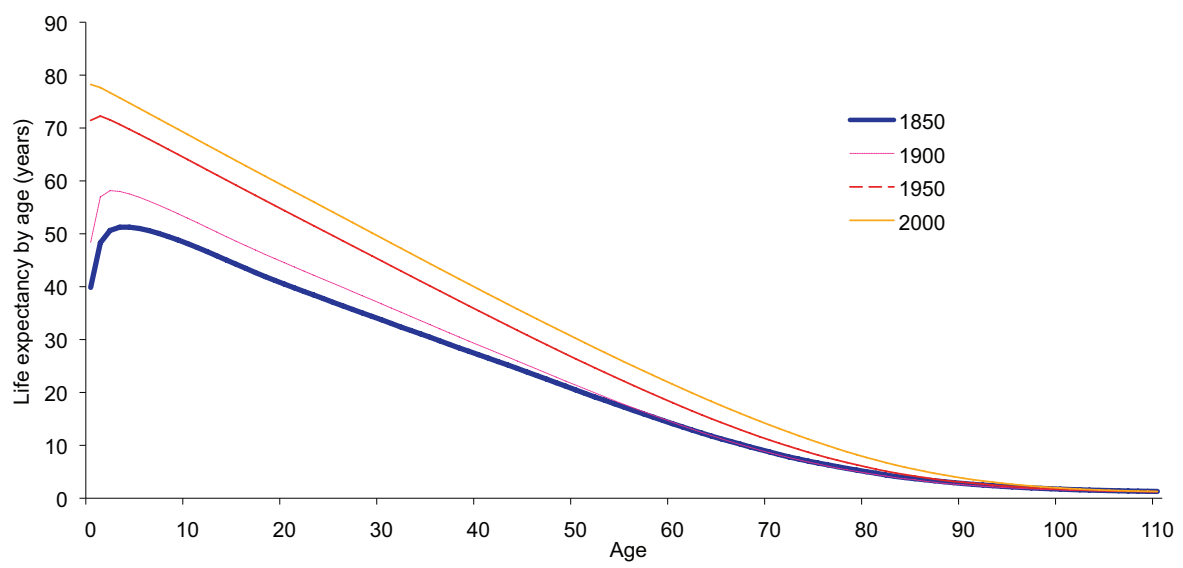

Source: Human Mortality Database (2010). 
The three main aims of our study are as follows:

i) To derive the relation between life expectancy at birth, age zero and infant mortality at the crossing in life expectancies.

ii) To determine regional clustering of the timing of the crossing in life expectancies at ages one and zero, first for developed countries, and then for all the regions of the world.

iii) To assess the balance or imbalance of subpopulations in the United States and use them as measures for within-country comparisons.

This study furthers our knowledge on life tables by showing the possibility of analyzing levels of infant mortality together with mortality after age one. The crossover between the life expectancies allows us to separate the world into countries that have passed this threshold point and those in which the life table imbalance persists. The latter countries are still in the paradoxical situation in which a child born this year has a shorter life expectancy than a child born last year and now age one. This can be thought of as a situation in which persons attaining age one obtain extra years of life expectancy, on top of the year already lived.

This imbalance in the life table can also be used to examine the black-white life expectancy gap (Kochanek, Maurer, and Rosenberg 1994; Harper et al. 2007). The disadvantaged survivorship of the American black population compared to the white population is well known (Eblen 1974; Cooper et al. 1981; Ewbank 1987; Verna and Smith 1988; Kochanek, Maurer, and Rosenberg 1994; Haines 2003; Klein 2004; Harper et al. 2007). Although the life expectancies for each sex and race are at different levels it can be asked if each of these life tables by sex and race has reached a balanced situation or not. We address this question in the current study.

This paper has five sections with the present introduction as the first. Data and methods are presented in sections two and three respectively. The fourth section contains the results and has three subsections: i) the crossover in life expectancies in industrialized countries, ii) the current situation of the rest of the countries of the world and iii) the comparison of the life tables for the black and white populations of the United States. Sections three and four also address the aims discussed above. Finally, the discussion is the fifth section.

\section{Data}

Five databases are used in this study: The Human Mortality Database (2010), Mortality Indicators Database from the United Nations (2008), Mortality Indicators from the World Health Organization (2008), US life tables by sex and race from the Centers for Disease Control and Prevention (1984-2006) and the Berkeley Mortality Database (2010). 
The Human Mortality Database (HMD) project contains detailed time series of mortality data and life tables for populations with virtually complete registration and census data. Data for all countries from this database are used and their annual period life expectancies at birth and at age one, are compared. For the life tables that show a crossing of life expectancies, $e_{0}=e_{1}$, we have also retrieved the age-specific death rates for age zero to one from this database.

The United Nations (UN) and the World Health Organization (WHO) produce mortality estimates and life tables on an annual basis for all state members. The majority of the countries of the world have incomplete data (partial counts of vital events and/or populations), and their life tables have to be constructed using a combination of direct and indirect methods (United Nations 1982; Murray et al. 2003; Wilmoth et al. 2009). Given the different methods used by each organization, the estimates coming from the UN and WHO for any given country do not always coincide. For the current project we have chosen the higher mortality scenario for each country, i.e. with a minimum life expectancy and maximum infant mortality. It should be noted that the infant mortality measures coming from the UN and WHO are calculated as the ratio of deaths in the first year of life in a given year divided by the births in that year. This ratio is what is normally known as the Infant Mortality Rate (IMR), although it is not a rate in the sense of occurrence over exposure (Preston, Heuveline, and Guillot 2001). In the present project we use the age-specific death rate at age zero to one, calculated as the ratio of deaths divided by the person-years lived between ages zero and one. Analysis of the historical mortality data from the Human Mortality Database (2010) shows that the two ratios are highly correlated $\left(R^{2}=0.997\right)$.

The Centers for Disease Control and Prevention (CDC) prepares life tables for the USA based on final numbers of deaths by year, and population estimates by year produced under a collaborative agreement with the US Census Bureau. This data source provides life tables by sex and race which are used in the analysis of the US population. To lengthen the US life table series by sex and race we have used the Berkeley Mortality Database (BMD). The latter database was replaced by the HMD, except for the detailed time series of mortality data and life tables for US black and white populations, which is only available in the BMD.

All the above-mentioned data sources were used in subsections of the results: i) The HMD is used to study the timing of the crossing in industrialized countries; ii) The UN and WHO databases are used to find the current status of the crossing in life expectancies for the different regions of the world; and iii) to address the gap in life table imbalance for the black and white populations of the USA data from CDC and from the BMD are used. 


\section{Methods}

\subsection{The crossing in life expectancies}

The life table gives the age structure of a population which is subjected to certain patterns of mortality interrelated by a set of mathematical functions. These specific mathematical relations describe the likelihood of persons in a population experiencing an event. The classical use of life tables is to study mortality, although other events can be studied: for example, first birth, first marriage, or exit from the job market (Preston, Heuveline, and Guillot 2001; Kintner 2004). In this section we derive some relations in the life table which give insight on the imbalanced life table situation mentioned above.

Life expectancy at age $x$, denoted as $e_{x}$, is the average number of years that a group of people reaching that age would live given the set of death rates observed in that year. Demographic measures change constantly over time and the life table functions are no exception. Several demographic textbooks list the fact that for a long time life expectancy was lower at birth than at age one. For example, (Chiang 1984: 118) mentions "As a rule, the expectation of life decreases as the age $x$ increases, with the exception of the first year of life where the reverse is true because of the high mortality during the first year." However, during the second half of the twentieth century most developed countries experienced a crossover of these two life expectancies. For example, for the United States total population the crossing of $e_{0}$ and $e_{1}$ occurred in 1979, 1977 for females and 1980 for males (see Table 1).

The crossing occurs when the inverse of the age-specific death rate for age zero to one equals the life expectancies at birth and at age one, and the relation is also true in the other direction,

$$
e_{0}=e_{1} \Leftrightarrow \frac{1}{{ }_{1} m_{0}}=e_{1},
$$

where the age-specific death rate for ages zero to one, ${ }_{1} m_{0}$, is defined as the ratio of deaths in the first year of life, ${ }_{1} d_{0}$, divided by the number of person-years lived between birth and age one, ${ }_{1} L_{0}$. Hereafter in the text we refer to the age-specific death rate in the first year of life as infant mortality.

Equation 1 is a simple relation that shows how life expectancy at birth is equal (or above) life expectancy at age one when the inverse of infant mortality is equal to (or greater than) the average length of life after age one. The proof of this simple equation comes from the fact that both measures, $e_{0}$ and $e_{1}$, are calculated from the same set of death rates after age one. Thus, life expectancy at birth can be written as a function of life expectancy at age one multiplied by the probability of surviving to this age plus the number of person-years lived between birth and age one: 


$$
e_{0}=e_{1} \ell_{1}+{ }_{1} L_{0},
$$

where $\ell_{1}$ is the probability of surviving from birth to age one in a life table whose radix is equal to one, $\ell_{0}=1$ (see Appendix for more details on this derivation). This probability can also be written as the difference of the initial survivors at age zero minus the number of deaths in the first year of life, and equation $2 \mathrm{a}$ can be re-written as:

$$
e_{0}=e_{1}\left(1-{ }_{1} d_{0}\right)+{ }_{1} L_{0},
$$

At the crossing, life expectancy at birth and at age one have the same value, substituting $e_{0}$ for $e_{1}$ on the left of equation $2 \mathrm{~b}$ and solving for life expectancy at age one yields the desired conclusion

$$
e_{1}=\frac{{ }_{1} L_{0}}{{ }_{1} d_{0}}=\frac{1}{{ }_{1} m_{0}} .
$$

The same relation is obtained if we start with life expectancy at age one equal to the inverse of infant mortality, and using equations $2 c, 2 b$ and $2 a$, obtain the equality of life expectancies at birth and age one.

The characteristic " $\mathrm{j}$ " shape of the age-pattern of mortality is seen across time and populations, although at different levels. The relation in equation 1 shows how mortality levels at different ages are related to each other. Other relations between levels of mortality at different ages have been used in demography to develop models of mortality estimation (Brass 1971; Murray et al. 2003; Wilmoth et al. 2009). The relation of mortality at different ages is relevant for this study, because before the crossing in life expectancies, higher infant mortality than expected - i.e., with respect to mortality levels at ages above one - is observed. In a balanced situation, mortality in the first year captured by the inverse of ${ }_{1} m_{0}$ corresponds to a level of mortality summarized by life expectancy at age one. However, mortality at older ages also influences this crossing and, as shown below, it can play a significant role in the crossing.

The significance of equation 1 is shown in the relation between mortality in the first year of life and in the ages after one in the age-aggregated measure of life expectancy. Figure 2 presents the trend in the three components of equation 1 for the total population of Sweden from 1850 to 2000.

During the twentieth century the reduction in infant mortality, captured by ${ }_{1} m_{0}$, turns into an exponential increase of its inverse. In 1965 the crossing in life expectancies occurred. Of particular interest here is the difference between these two life expectancies 
that initially are apart by -6.7 years in 1850 (higher $e_{1}$ than $e_{0}$ ) and the difference changes to 0.8 of a year by 2000 .

Figure 2: $\quad$ Life expectancies at birth $\left(e_{0}\right)$ and at age one $\left(e_{1}\right)$ and the inverse of the infant mortality $\left(1 /{ }_{1} m_{0}\right)$ for the Swedish total population from 1850 to 2005

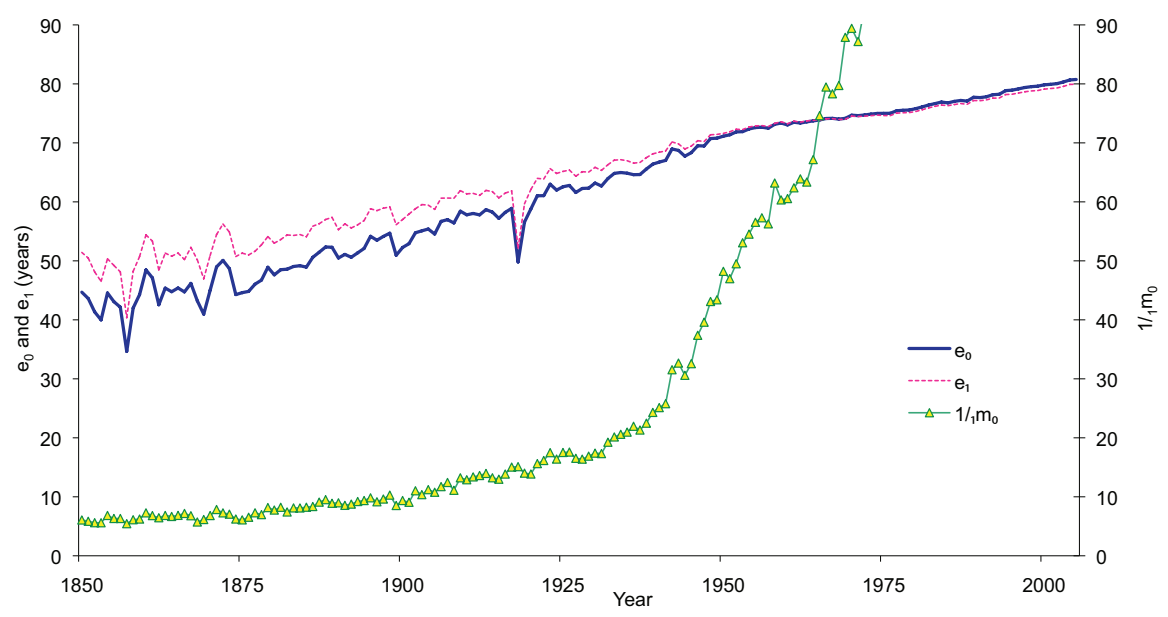

Source: Human Mortality Database (2010). Note only values of inverse infant mortality below 90 are shown.

\subsection{The difference in life expectancies and its components}

We further analyze the components of the change over time in the difference in life expectancies (at birth minus at age one). This difference in life expectancies is zero when the condition in equation 1 is fulfilled. Initially this difference is negative, but moves to positive values after the life table achieves a balanced situation. Figure 3 a shows the life expectancies at birth and age one, their gap and the change per decade of this gap for Japanese males from 1960 to 2007.

The crossing in life expectancies for Japanese males occurs in 1971. This crossing occurred during a time that both measures were increasing from values of 65.3 and 66.5 years for $e_{0}$ and $e_{1}$ respectively in 1960 , to 79.2 and 78.4 in 2007 respectively. The difference between life expectancies is reduced significantly in the 1960s from a gap of -1.2 year, with higher $e_{1}$, in 1960 to -0.1 in 1970 . This is a reduction of more than 
one year denoted in the figure as the bar of "Change in $e_{0}-e_{1}$ ". However, the remaining decades show a more modest reduction in the gap.

Figure 3a: $\quad$ Male life expectancies at birth $\left(e_{0}\right)$ and at age one $\left(e_{1}\right)$, their difference $\left(e_{0}-e_{1}\right)$, and the change of the difference by decade, Japan 1960-2007

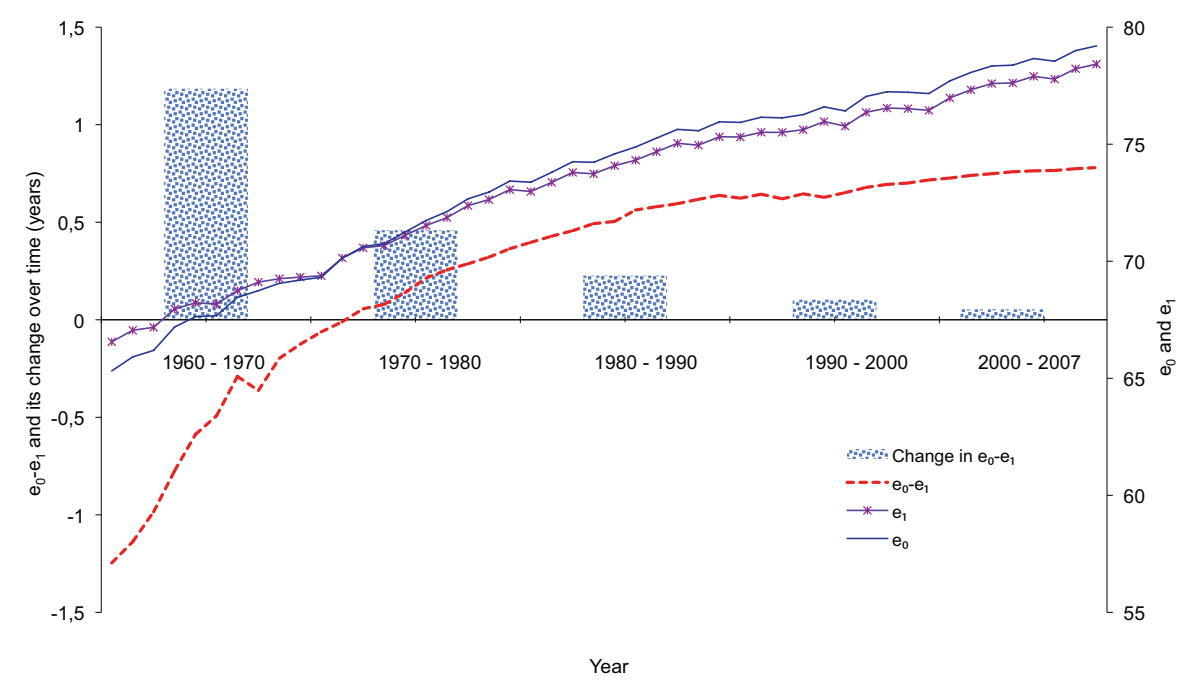

Source: Authors' calculations based on the Human Mortality Database (2010).

This change in the difference can be of further interest if the focus is on explaining trends over time in the gap between life expectancies at birth and at age one. In equation 2a, life expectancy at birth depends on three terms. Two components describe the mortality experience in the first year of life: probability of surviving to age one and person-years lived between birth and age one. The third term is life expectancy at age one which captures the experience of mortality after age one. The change in the difference between life expectancies is thus dependent on changes before and after age one. In the Appendix we propose a method to disentangle the changes in the gap over time due to reductions in mortality in the first year of life, and those due to reductions in mortality after age one. For notation in the Figures we refer to these as the "Change in $e_{0}-e_{1}$ " explained by "Changes below age one" and by "Changes above age one". The top panel of Table 2 and Figure $3 \mathrm{~b}$ show the components of change in the difference for Japanese males' life expectancies for the decades between 1960 and 2007.

As observed in Table 2 and Figure 3b, the large decline in the life expectancy gap 
Figure 3b: Difference between male life expectancies at birth and age one $\left(e_{0}-e_{1}\right)$ and components of its change by decade,

Japan 1960-2007

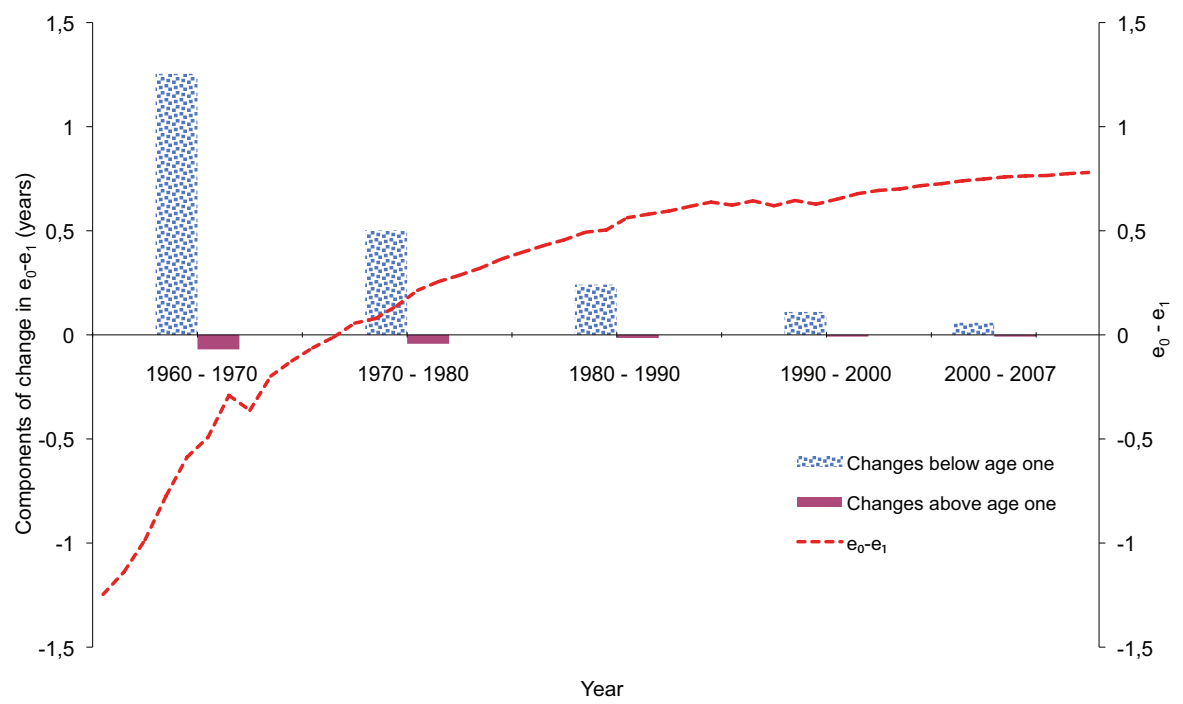

Source: Authors' calculations based on the Human Mortality Database (2010).

for Japanese males is due mostly to great improvements in the first year of life. This can be observed in the high "Changes below age one" component. Below, we discuss the time trends for other populations with situations where the "Changes above age one" component is as important as the "Changes below age one" component.

\section{Results}

\subsection{The crossover in industrialized countries}

For industrialized countries, Table 1 and Figure 4 show the timing of the crossing of $e_{0}$ and $e_{1}$. There is considerable variation in the timing of the crossover. Table 1 also shows the life expectancy and the infant mortality level at that time. 


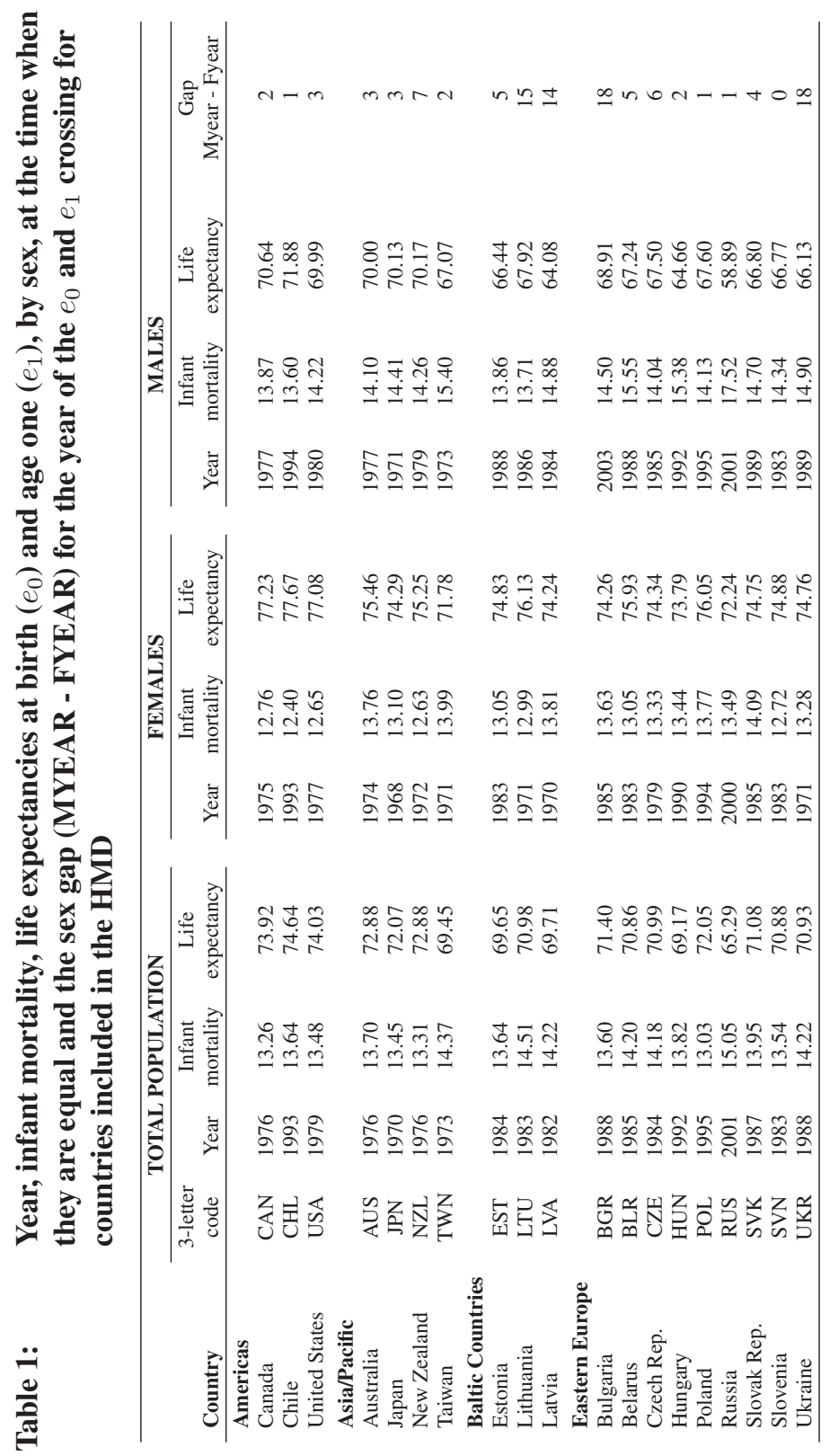


Canudas-Romo \& Becker: The imbalance in the life table

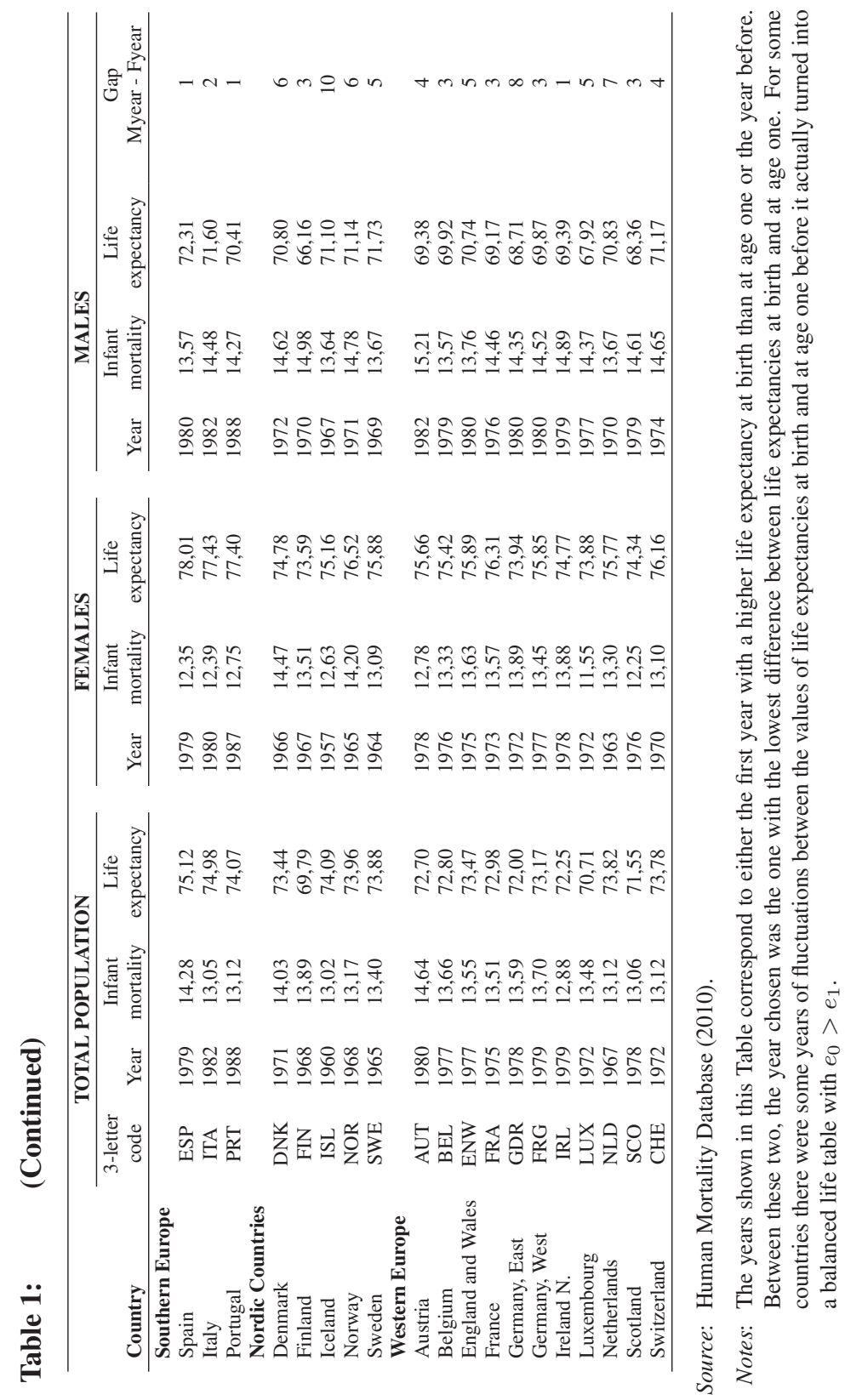


Figure 4: $\quad$ Life expectancy at birth at the year of the first crossing with life expectancy at age one, total population by country

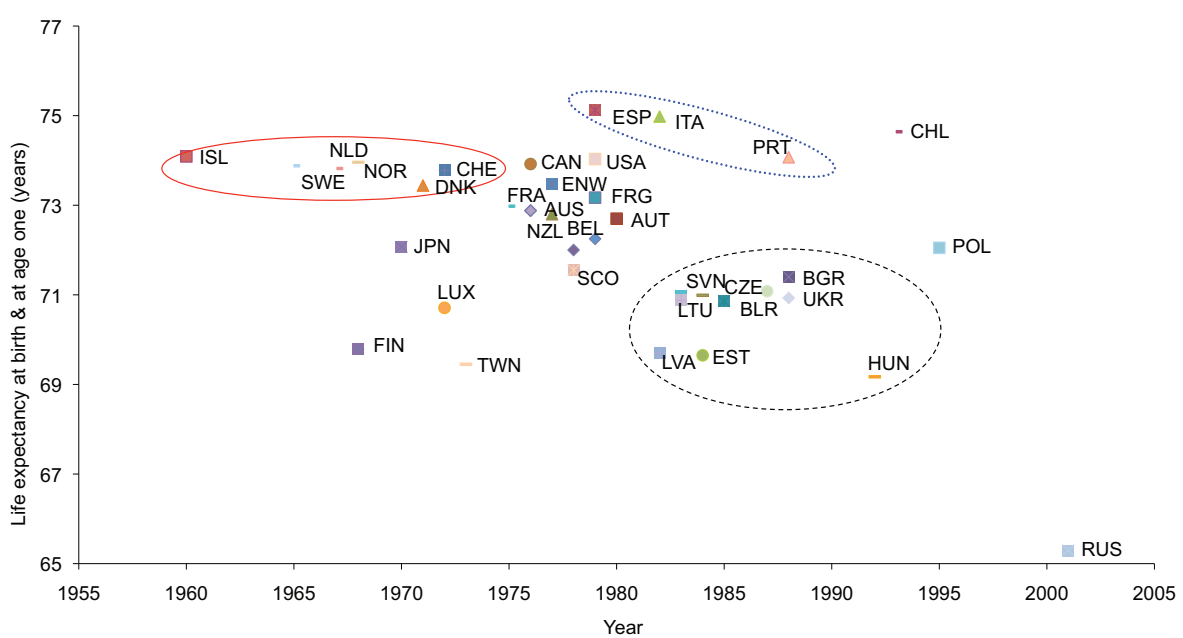

Source: Human Mortality Database (2010); Table 1 has the countries 3-letter codes.

The first crossing in the world occurred in 1957 for Icelandic females, for males in the same country this was not observed until 1967. The time of the male crossover is later than that of females for all analyzed countries except Slovenia. However, the variation in time is large with one year difference for Portugal, Russia and Spain, and 14 to 18 years difference in Latvia, Lithuania, Bulgaria and Ukraine. The crossings in life expectancies occurred in the range of infant mortality of 11.6 to 14.5 deaths per thousand live births for females and of 13.6 to 17.5 for males. The level of life expectancy varied between the values of 71.8 to 78.0 years for females and 58.9 to 72.3 years for males. The larger variation in levels of life expectancy among males than among females (13.4 versus 6.2 years respectively) is due to the very low life expectancy at the crossing for Russia.

Figure 4 shows a clear regional clustering of the crossing of the life expectancies. The Nordic countries, together with Switzerland and the Netherlands, were among the first to experience a balanced life table. In the Eastern European region by contrast, the first crossings are not observed until the 1980s. Another unexpected finding is the regular patterns in levels of life expectancy at which the crossing occurs: Eastern Europe at low levels, Scandinavia, Western and Central Europe at middle levels, and finally Southern Europe at high levels. 
The clear clusters of life expectancy at the time of the crossing observed in Figure 4 , are not replicated for infant mortality. For example, Danish females have the highest infant mortality of any of the females' values, even when their life expectancy was at a middle level at the crossing. Clearly mortality at ages other than the first year of life have a role in determining the time of the crossing. To further explain the crossing in life expectancies we look in detail at the interplay between the components of equation 1 .

The decomposition of the change over time in the difference between life expectancy at birth minus life expectancy at age one allows study of the components of this change (see Appendix for details on the decomposition). The components have been aggregated into those that correspond to "Changes below age one" and "Changes above age one". Across countries included in the HMD, the changes observed in the two components are clustered into three types:

(1) a decline in both components over time,

(2) fluctuations over time with an apparent declining trend but interrupted by mortality crises, and finally

(3) a bell shape trend with a peak in one of the periods and decline thereafter.

Table 2 and Figures $3 b, 5 a$ and $5 b$ present the trends in the life expectancy difference, $e_{0}-e_{1}$, and components of its change during each of the decades since the 1960s up to the first years of the 2000s for males (for Japan in Figure 3b, Russia in Figure 5a and the United States in Figure 5b). The selected countries represent the three types of changes mentioned above: Japan for (1), Russia for (2) and USA for (3).

In Table 2 and Figures 3b, 5a and 5b, it can be observed that by 1960, the three countries had male life expectancy at age one above life expectancy at birth by more than one year. In the 1960s, changes in mortality in the first year of life accounted for almost all the reduction in the difference between life expectancies in Japan (see Figure 3b and first panel of Table 2). At the end of this decade, both Russia and the USA stood ready to achieve the crossover with a difference of half a year between the two life expectancies. However, Russia, as well as other Eastern European countries, entered a mortality crisis in the 1970s that delayed the crossover and kept their life table imbalanced. A similar situation is observed in Figure 5a in the 1990s. Part of the explanation is the slow progress made in survivorship in the first year of life. However, the delayed crossover was shortened by the increase in mortality at adult ages, captured by the "Changes above age one", that helped to reduce the life expectancy gap in Russia in the 1960s, 1970s and 1990s. That is, life expectancy at age one declined, and the gap between this and life expectancy at birth also decreased. 
Table 2: $\quad$ Difference between male life expectancies at birth and age one $\left(e_{0}-e_{1}\right)$ and components of its change by decade for Japan, Russia and the United States 1960-2007*

\begin{tabular}{|c|c|c|c|c|c|c|}
\hline \multicolumn{7}{|c|}{ Japan } \\
\hline year $=t$ & 1960 & 1970 & 1980 & 1990 & 2000 & 2007 \\
\hline$e_{0}(t)$ & 65,31 & 69,32 & 73,38 & 75,93 & 77,70 & 79,20 \\
\hline$e_{1}(t)$ & 66,56 & 69,38 & 72,98 & 75,31 & 76,97 & 78,42 \\
\hline$D(t)=e_{0}(t)-e_{1}(t)$ & $-1,25$ & $-0,06$ & 0,40 & 0,62 & 0,73 & 0,78 \\
\hline$D(t+10)-D(t)$ & 1,18 & 0,46 & 0,23 & 0,10 & 0,05 & \\
\hline$A=$ Change below age 1 & 1,25 & 0,50 & 0,24 & 0,11 & 0,06 & \\
\hline$B=$ Change above age 1 & $-0,07$ & $-0,04$ & $-0,01$ & $-0,01$ & 0,00 & \\
\hline$A+B=$ Total change & 1,18 & 0,46 & 0,23 & 0,10 & 0,05 & \\
\hline \multicolumn{7}{|c|}{ Russia } \\
\hline year $=t$ & 1960 & 1970 & 1980 & 1990 & 2000 & 2008 \\
\hline$e_{0}(t)$ & 63,67 & 63,07 & 61,38 & 63,76 & 58,99 & 61,79 \\
\hline$e_{1}(t)$ & 65,33 & 63,73 & 61,95 & 64,02 & 59,04 & 61,39 \\
\hline$D(t)=e_{0}(t)-e_{1}(t)$ & $-1,66$ & $-0,66$ & $-0,57$ & $-0,26$ & $-0,06$ & 0,40 \\
\hline$D(t+10)-D(t)$ & 1,00 & 0,09 & 0,31 & 0,20 & 0,45 & \\
\hline$A=$ Change below age 1 & 0,96 & 0,04 & 0,36 & 0,10 & 0,48 & \\
\hline$B=$ Change above age 1 & 0,04 & 0,05 & $-0,05$ & 0,10 & $-0,02$ & \\
\hline$A+B=$ Total change & 1,00 & 0,09 & 0,31 & 0,20 & 0,45 & \\
\hline \multicolumn{7}{|c|}{ United States } \\
\hline year $=t$ & 1960 & 1970 & 1980 & 1990 & 2000 & 2006 \\
\hline$e_{0}(t)$ & 66,63 & 67,02 & 69,99 & 71,87 & 74,28 & 75,50 \\
\hline$e_{1}(t)$ & 67,66 & 67,62 & 69,98 & 71,64 & 73,86 & 75,06 \\
\hline$D(t)=e_{0}(t)-e_{1}(t)$ & $-1,03$ & $-0,60$ & 0,00 & 0,23 & 0,42 & 0,44 \\
\hline$D(t+10)-D(t)$ & 0,44 & 0,60 & 0,22 & 0,19 & 0,02 & \\
\hline$A=$ Change below age 1 & 0,43 & 0,65 & 0,24 & 0,21 & 0,03 & \\
\hline$B=$ Change above age 1 & 0,00 & $-0,04$ & $-0,02$ & $-0,02$ & $-0,01$ & \\
\hline$A+B=$ Total change & 0,44 & 0,60 & 0,22 & 0,19 & 0,02 & \\
\hline
\end{tabular}

Source: Human Mortality Database (2010).

Notes: The last year with available data is 2007 for Japan, 2008 for Russia and 2006 for the United States. 
Figure 5a: Difference between male life expectancies at birth and at age one $\left(e_{0}-e_{1}\right)$ and components of its change by decade, Russia 1960-2008

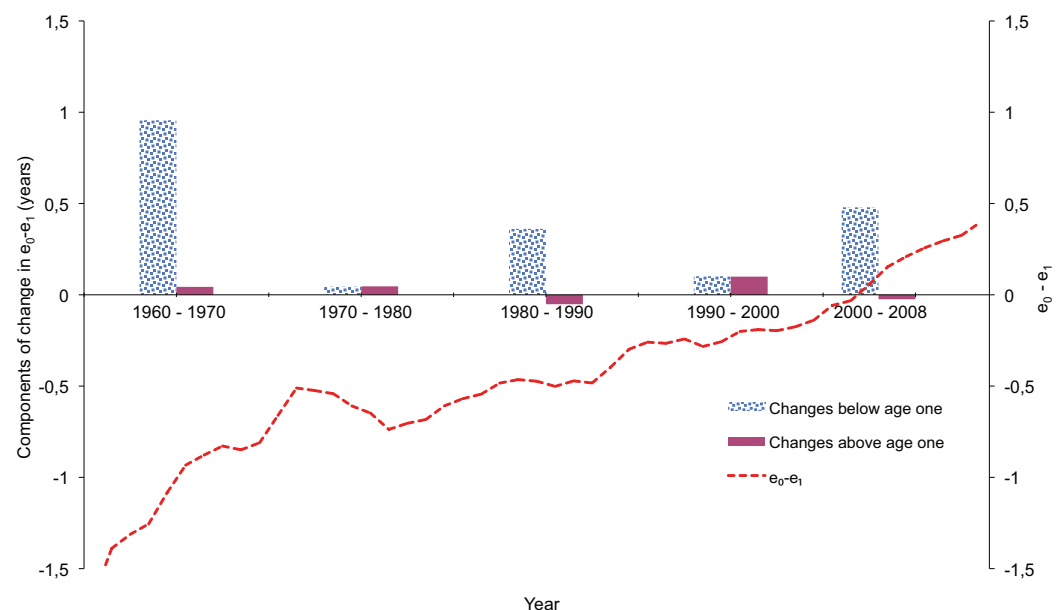

Figure 5b: Difference between male life expectancies at birth and age one $\left(e_{0}-e_{1}\right)$ and components of its change by decade, United States 1960-2006

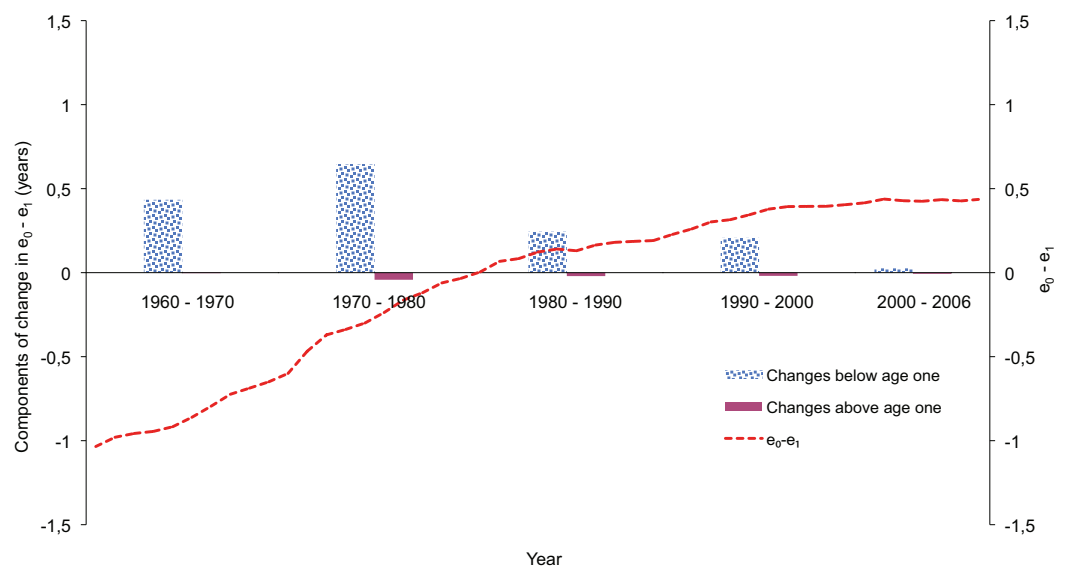

Source: Authors' calculations based on Human Mortality Database (2010). 
Figure 6: $\quad$ Infant mortality rate and life expectancy at birth for countries members of the WHO and UN, and not included in the HMD, latest available information from WHO and $\mathrm{UN}$

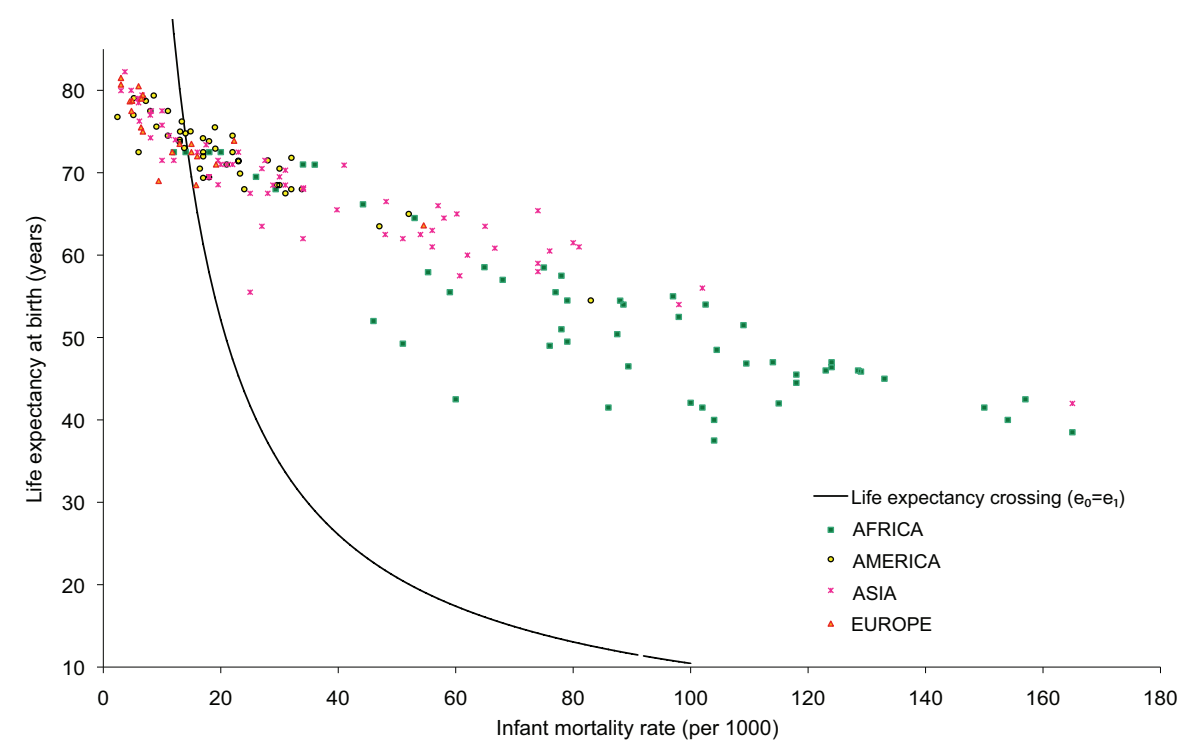

Source: United Nations (2008) and World Health Organization (2008).

\subsection{The crossover in countries of the world}

The United Nations (2008) and the World Health Organization (2008) databases can be used to present the recent situation of the world with respect to the crossing in life expectancies and the imbalance in life tables. Figure 6 presents the situation of the countries of the world in 2005 with respect to their life expectancy at birth and infant mortality. Four regions of the world are included in Figure 6, according to the United Nations macro regions: Africa, America, Asia/Oceania, and Europe. Also included is the line in where life expectancy at age one is equal to the inverse of infant mortality, as expressed in equation 1.

Most of the European countries have achieved a balanced life table, and are located to the left of the curve of equation 1 . On the other hand, only the island nations of the Republics of Seychelles and Mauritius have achieved this situation in Africa. 
Asia/Oceania and the Americas have some of their countries still experiencing the imbalance in life tables while in others life expectancy at birth has the higher value. Although this plot presents the current situation, it cannot be reliably used to extrapolate possible crossing times and levels of mortality. As shown in Figure $3 \mathrm{~b}$ for Russia, unexpected retrocession in mortality can delay or accelerate the crossing of the two life expectancies.

The countries included in the HMD have been excluded from Figure 6a, but a comparison using results from Table 1 and Figure 4 is instructive. The life expectancy crossing occurred between the levels of 65 to 75 years for countries included in the HMD. For countries in Figure 6 experiencing the crossing in recent years, this occurs in some cases at levels of life expectancy higher than 75 years. The interplay between levels of mortality below and above age one have caused these high life expectancies at the crossing. For example, in Figure 4 Southern Europe had the highest levels of life expectancy at the crossing. In these countries, life expectancy at age one had reached high levels as a consequence of high survivorship once the first year of life had passed. Infant mortality had also reduced, but it had to reach very low values to trigger the crossing. Similar circumstances were likely present in countries, such as those in Figure 6, where the crossing was experienced at levels of life expectancies above age 75 .

\subsection{The imbalance in the life tables for the black and white populations of the USA}

The black-white life expectancy gap in the USA can also be studied in terms of the imbalance in the life tables. Period life tables by race and sex for the USA since 1968 are used to study the crossover in life expectancies. As observed in Figure 7a, the trend for all the groups has been an increase in life expectancy and decline in infant mortality over time. All groups have moved from right to left in Figure 7a from high infant mortality to lower levels. The timing of the crossing in the white population was 1974 for females and 1977 for males. This can be observed in Figure 7a by noting that the values for the white population are mainly to the left of the line where $e_{0}=e_{1}=1 /{ }_{1} m_{0}$. These years are earlier than those shown in Table 1 for the USA population of 1977 for females and 1980 for males, where all races were combined. The female black population experienced this crossing in 1996 and black males are close to accomplishing this.

The gap between the black and white life expectancies has been extensively studied (e.g.; Eblen 1974; Cooper et al. 1981; Ewbank 1987; Verna and Smith 1988; Kochanek, Maurer, and Rosenberg 1994; Haines 2003; Klein 2004; Harper et al. 2007). The novelty of the present results is to show not only that the black population has higher levels of mortality, but also that its life table is, until recently, in an imbalanced state. This is due to the high levels of infant mortality still prevalent which affect life expectancy at birth, but not at age one, and as a consequence $e_{0}<e_{1}$. However, part of the explanation is 
also found at older ages, as shown in Figure $7 \mathrm{~b}$, where the components of the change over time in the difference between life expectancies, $e_{0}-e_{1}$, of African American males are examined.

Figure 7a: Infant mortality and life expectancy at birth for American females and males by race (white $\&$ black), 1968-2003

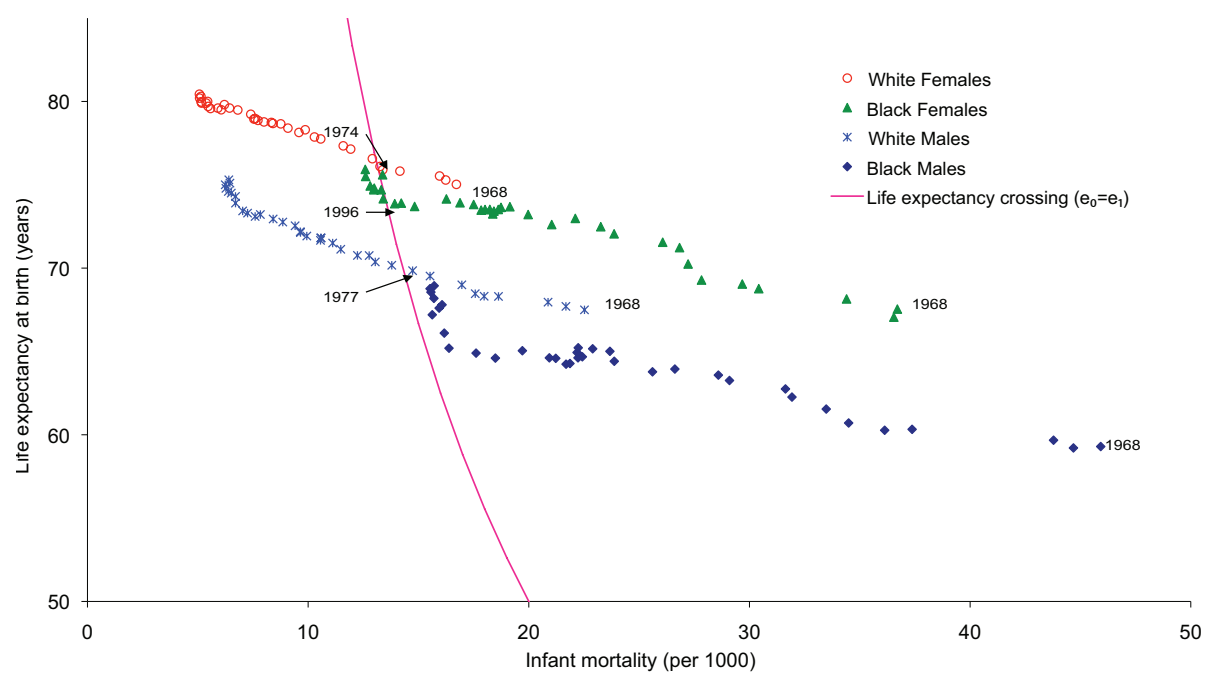

Source: $\quad \operatorname{BMDB}(2010)$ and CDC (1984-2006).

Figure $7 \mathrm{~b}$ is analogous to Figures $3 \mathrm{~b}, 5 \mathrm{a}$ and $5 \mathrm{~b}$, but instead of national populations, it shows a subpopulation in the USA. From 1968 until 1995 the transition toward a balanced life table for African American males showed similar progress as the other subpopulations had done earlier. Between 1995 and 2000, very slow progress in preventing deaths in the first year of life combined with more evident reductions for older age groups resulted in a slight increase in the life expectancies gap. This can be observed in Figure $7 \mathrm{~b}$ for the period 1995-2000, where the component for "Changes above age one" is similar to "Changes below age one", only negative. In the most recent years further improvements in mortality at advanced ages have occurred, although a stagnation in mortality is evident in the first year of life. This illustration clearly exemplifies the relevance that adult mortality has in understanding the crossover in life expectancies. 
Figure 7b: Difference between male life expectancies at birth and age one $\left(e_{0}-e_{1}\right)$ for the black American population and components of its change for every five years, 1968-2003

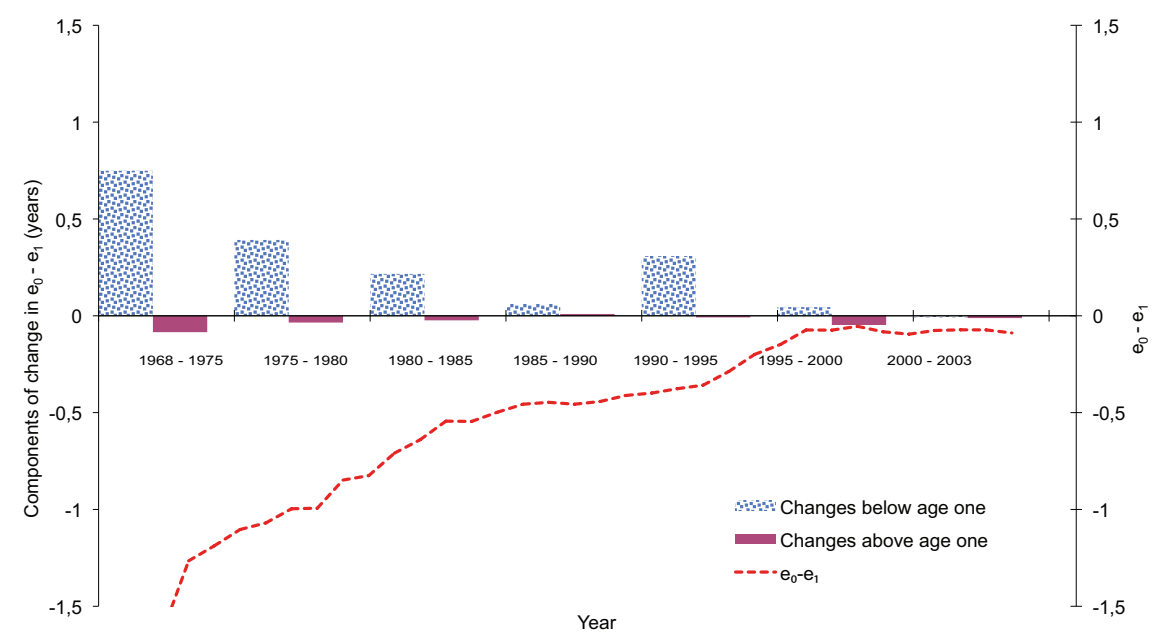

Source: Author's calculations based on BMDB(2010) and CDC (1984-2006).

\section{Discussion}

The motivation for this research was to find the relations among the functions of an imbalanced life table, i.e. when life expectancy at birth is lower than at age one, $e_{0}<e_{1}$. This imbalance ends when $e_{0}=e_{1}$. Equation 1 is a simple relation between infant mortality and life expectancies at birth and age one and it is central to explicating the mechanisms of the crossover.

The demographic transition has been described as a period of decline from high to low levels of fertility and mortality (Notestein 1945; Davis 1945; Lee 2003). The mortality aspect of this transition has been characterized by, among other things, the increase in life expectancy at birth. However, the causes of this increase have changed over time from a dominance of infant and child mortality reductions to a dominance of adult mortality reductions (Wilmoth 1997). During this transition of differential mortality declines by age, imbalanced life tables have been observed. For countries where historical 
information on mortality is available, it is possible to analyze these disparities over time and region.

The illustration of the crossover in life expectancy observed in the HMD data suggests that socio-cultural, economic, and political factors that influence the intermediate factors that shape the mortality patterns in each country have traversed borders. In other words, the timing and mortality level at which populations progress from an imbalanced life table to a balanced one depend on the specific characteristics of each country, but also on regional characteristics. For example, the trends in mortality in the Baltic countries, Latvia and Lithuania, are very similar (Kasmel et al. 2004). Therefore, it is not surprising to find similar gaps between the female and male timing for the crossing in life expectancies (Table 1 and Figure 4). However, it is surprising to find these countries together with Bulgaria and Ukraine with the extreme of over 14 years difference between the female and male timing, while other eastern European countries only differ by a couple of years. Sex differentials in infant mortality vary widely across countries (Fuse and Crenshaw 2006). However, in the context of the Baltic countries this is probably not the only factor. The great disparity between females and males comes from a combination of infant mortality and high levels of adult male mortality. Furthermore, differentials among subpopulations within each country could also drive some of these results (Leinsalu, Vågerö, and Kunst 2004). It should be noted that in Estonia, the third Baltic country, females were close to a crossing in the 1970s, similar to the situation for the other two countries, and thus a similar gender gap in the timing of the crossing might have been observed.

This analysis can be considered as a within-population examination of infant mortality versus mortality after age one. However, the level of mortality of a population is a key element for comparison across populations or across time. As shown in Figure 6, the world is highly heterogeneous regarding the current state of balance or imbalance in life tables. We set a threshold that divides countries into those that have achieved a balanced situation, and those that have not. This international comparison also reveals an interesting pattern of levels of life expectancy at the crossing. The countries that experienced the crossing early did this at levels of life expectancy below age 75, as seen for European countries, as well as Australia, Canada, Japan, New Zealand, and the United States (see Table 1). However, when studying the crossing for countries outside those included in the HMD the results suggest that the crossing is occurring at expectations beyond age 75 (see Figure 6). This is also observed when examining model life tables created by the UN (1982) and Coale and Demeny (1983) for the crossing (analysis not shown). Relevant measures for explicating this crossing at higher life expectancies are the levels of mortality before and after age one. For example, this can occur when the latter age group experiences greater mortality reductions than the former. Studies of infant and child mortality declines in Europe have shown that mortality between ages one and five 
declined before mortality in the first year of life, followed by a second phase of decline where mortality in infancy declined faster than in the later childhood years (Hill 1995). Life expectancy at age one captures the first type of reduction, and is independent of the level of mortality in the first year of life. In this setting, equation 1 suggests that infant mortality has to go down further to trigger the crossing.

The opposite situation is observed when a country achieves the crossing at an extremely low level of life expectancy-for example, the result for Russian males with a crossing at life expectancy of 59 years. Russian mortality in infancy and childhood, as well as in old age, was practically unaffected by the crisis in the 1990s, as opposed to the excess mortality among working age men (Leon, Shkolnikov, and McKee 2009). Another example of reversals in mortality is in the emergence of HIV/AIDS as a leading cause of adult mortality (Ahmad, Lopez, and Inoue 2000). The two life expectancies could be getting closer in highly affected countries, if infant mortality is not increasing as well.

The within-population comparison can also be used to contrast subgroup differences. Populations can be compared on how infant versus mortality after age one have changed. The black population in the USA lags behind its white counterpart not only on levels of survivorship but also on the timing of the crossover between life expectancies at birth and age one (see Figures $7 \mathrm{a}$ and $7 \mathrm{~b}$ ). This is partly due to the excess infant mortality still prevalent among blacks as compared with other races (Martin et al. 2005). It is also a consequence of the mortality levels at adult ages which have progressed and regressed with unexpected fluctuations (Harper et al. 2007). For example, the reduction in young adult mortality among black males in recent years will be causing a further delay in the life expectancy crossing unless it is accompanied by further reductions in infant mortality.

Research is needed into the factors that have produced all the above mentioned trends. However, three corollaries can be extended from the results presented here:

- No single measure of mortality can fully describe the mortality situation of a population. An analysis of mortality changes or trends solely based on life expectancy at birth hides fundamental changes that might be occurring at specific ages. Analogously, an index of mortality for the first year of life without the context of mortality at other ages or an age-aggregated mortality measure of the population under study is also incomplete. The present analysis suggests that alternative indexes at different ages offer the possibility of an internal comparison of levels of mortality in the population under study. Relations between these complementary indexes, as those shown here, could help the study of possible excess mortality at certain ages. This is particularly important for developing countries that are still experiencing an imbalanced life table and for studies of historical trends in any population.

- The results presented here correspond to period life tables. The youngest cohort life 
tables available in the Human Mortality Database (2010) are for the cohort born in 1915 which did not have a crossover in life expectancies for any country. In other words they have not achieved a minimum of infant mortality that corresponds to life expectancy at age one. Goldstein and Wachter (2006) have noted how period measures of mortality follow trends similar to cohort measures but lagged by some years. For example, the Swedish cohort of 1915 had a life expectancy of 66.37 years which was not observed until the period life table of 1939. We then would expect to observe the crossings in life expectancies, at birth and age one, earlier in the cohort life tables than in the period life tables. To explore this will necessitate waiting until persons from the cohorts born in the first half of the twentieth century have died.

- Finally, equation 1 can be generalized to older ages as shown in the Appendix for child mortality, but also for other ages. For example, in low mortality countries, neonatal rates of 2 deaths per thousand live births are not unusual (World Health Organization 2008). A neonatal rate is not a rate in terms of events over persons exposed (Preston, Heuveline, and Guillot 2001), but it can be transformed to a rate by changing the denominator into a measure of person-years lived. The neonatal rate is then approximately equal to a death rate of 24 deaths per thousand person-years. The inverse of this death rate is 41.6 , which is much lower than the current life expectancy at birth in low mortality countries ( 80 years). Thus, from equation 2 it can then be concluded that life expectancy at age 28 days is higher than at age zero for populations with this level of neonatal mortality. This trend changes once the inverse of the neonatal rate is equal to life expectancies at birth and at age 28 days. More generally, life expectancies at birth and at age " $x$ " are equal when $e_{0}=e_{x}=1 /{ }_{x} m_{0}$, regardless of whether years, months or days are the unit of analysis. 


\section{References}

Ahmad, O., Lopez, A.D., and Inoue, M. (2000). The decline in child mortality: A reappraisal. Bulletin of the World Health Organization 10(78): 1175-1191. doi:10.1590/S0042-96862000001000004.

Berkeley Mortality Database (2010). Berkeley mortality database. Berkeley, USA: University of California. Http://www.demog.berkeley.edu (4/02/2010).

Brass, W. (1971). On the scale of mortality. In: Brass, W. (ed.) Biological Aspects of Demography. London: Taylor \& Francis.

Canudas-Romo, V. and Engelman, M. (2009). Maximum life expectancies: Revisiting the best practice trends. Genus LXV(1): 59-79.

Centers for Disease Control and Prevention (1984-2006). Vital statistics of the United States 1980, 1981, ..., 1995. National Vital Statistics Report 1996, 1997, ..., 2003. Http://www.cdc.gov/nchs/products/pubs/pubd/lftbls/lftbls.htm (13/01/2008).

Chiang, C.L. (1984). Life table and its applications. Malabar, Florida: Robert E. Krieger Publishing.

Coale, A.J. and Demeny, P. (1983). Regional model life tables and stable populations. New York: Academic Press, 2nd edition ed.

Cooper, R., Steinhauer, M., Schatzkin, A., and Miller, W. (1981). Improved mortality among u.s. blacks, 1968-1978: The role of antiracist struggle. International Journal of Health Services 11(4): 511-522. doi:10.2190/WJEP-VB83-GAUT-XEJR.

Davis, K. (1945). The world demographic transition. Annals of the American Academy of Political and Social Science 237(1): 1-11. doi:10.1177/000271624523700102.

Dublin, L.I. (1923). The possibility of extending human life. Metron 3(2): 175-197.

Dublin, L.I. and Lotka, J.A. (1934). The history of longevity in the United States. Human Biology 6(1): 43-86.

Eblen, J.E. (1974). New estimates of the vital rates of the united states black population during the nineteenth century. Demography 11(2): 301-320. doi:10.2307/2060565.

Ewbank, D.C. (1987). History of black mortality and health before 1940. The Milbank Quarterly, Currents of Health Policy: Impacts on Black Americans 65(1-Part 1): 100-128. doi:10.2307/3349953.

Finch, C.E. and Crimmins, E.M. (2004). Inflammatory exposure and historical changes in human life-spans. Science 305(5691): 1736-1739. doi:10.1126/science.1092556. 
Frisbie, W.P., Song, S., Powers, D.A., and Street, J.A. (2004). The increasing racial disparity in infant mortality: Respiratory distress syndrome and other causes. Demography 41(4): 773-800. doi:10.1353/dem.2004.0030.

Fuse, K. and Crenshaw, E.M. (2006). Gender imbalance in infant mortality: A cross-national study of social structure and female infanticide. Social Science \& Medicine 62(2): 360-374. doi:10.1016/j.socscimed.2005.06.006.

Galobardes, B., Lynch, J.W., and Smith, G.D. (2004). Childhood socioeconomic circumstances and cause-specific mortality in adulthood: Systematic review and interpretation. Epidemiology Review 26: 7-21. doi:10.1093/epirev/mxh008.

Goldstein, J.R. and Wachter, K.W. (2006). Relationships between period and cohort life expectancy: Gaps and lags. Population Studies 60(3): 257-269. doi:10.1080/00324720600895876.

Haines, M.R. (2003). Ethnic differences in demographic behavior in the United States: Has there been convergence? Historical Methods 36(4): 157-195. doi:10.1080/01615440309604818.

Harper, S., Lynch, J., Burris, S.J.D., and Smith, G.D. (2007). Trends in the black-white life expectancy gap in the United States, 1983-2003. The Journal of the American Medical Association 297(11): 1224-1232. doi:10.1001/jama.297.11.1224.

Hill, K. (1995). The decline in childhood mortality. In: Simon, J.L. (ed.) The state of humanity. Boston: Blackwell: 30-36.

Horiuchi, S. (1991). Assessing the effects of mortality reduction on population ageing. Population Bulletin of the United Nations 31(2): 38-51.

Human Mortality Database (2010). Human mortality database. Berkeley, USA: University of California, and Rostock, Germany: Max Planck Institute for Demographic Research. Http://www.mortality.org (4/02/2010).

Hummer, R.A., Powers, D.A., Pullum, S.G., Gossman, G.L., and Frisbie, W.P. (2007). Paradox found (again): Infant mortality among the Mexican-origin population in the United States. Demography 44(3): 441-457. doi:10.1353/dem.2007.0028.

Kannisto, V. (2001). Mode and dispersion of the length of life. Population: An English Selection 13(1): 159-171.

Kannisto, V., Lauritsen, J., Thatcher, A.R., and Vaupel, J.W. (1994). Reduction in mortality at advanced ages: Several decades of evidence from 27 countries. Population and Development Review 20(4): 793-810. doi:10.2307/2137662. 
Kasmel, A., Helasoja, V., Lipand, A., Prättälä, R., Klumbiene, J., and Pudule, I. (2004). Association between health behavior and self-reported health in Estonia, Finland, Latvia and Lithuania. The European Journal of Public Health 14(1): 32-36. doi:10.1093/eurpub/14.1.32.

Kintner, H.J. (2004). The life table. In: Siegel, J.S. and Swanson, D.A. (eds.) The methods and materials of demography, Second Edition. San Diego, USA: Elsevier Academic Press.

Kitagawa, E. (1955). Components of a difference between two rates. Journal of the American Statistical Association 50(272): 1168-1194. doi:10.2307/2281213.

Klein, H.S. (2004). A population history of the United States. Cambridge, England: Cambridge University Press.

Kochanek, K.D., Maurer, J.D., and Rosenberg, H.M. (1994). Why did black life expectancy decline from 1984 through 1989 in the United States? American Journal of Public Health 84(6): 938-944. doi:10.2105/AJPH.84.6.938.

Kramer, M.S., Platt, R.W., Yang, H., Haglund, B., Cnattingius, S., and Berjso, P. (2002). Registration artifacts in international comparisons of infant mortality. Paediatric and Perinatal Epidemiology 16: 16-22.

Lee, R. (2003). The demographic transition: Three centuries of fundamental change. The Journal of Economic Perspectives 17(4): 167-190. doi:10.1257/089533003772034943.

Leinsalu, M., Vågerö, D., and Kunst, A.E. (2004). Increasing ethnic differences in mortality in Estonia after the collapse of the Soviet Union. Journal of Epidemiology and Community Health 58(7): 583-589. doi:10.1136/jech.2003.013755.

Leon, D.A., Shkolnikov, V.M., and McKee, M. (2009). Alcohol and Russian mortality: A continuing crisis. Addiction 104: 1630-1636. doi:10.1111/j.1360-0443.2009.02655.x.

Martin, J.A., Kochanek, K.D., Strobino, D.M., Guyer, B., and MacDorman, M.F. (2005). Annual summary of vital statistics 2003. Pediatrics 115(3): 619-634. doi:10.1542/peds.2004-2695.

Murray, C.J.L., Ferguson, B.D., Lopez, A.D., Guillot, M., Salomon, J.A., and Ahmad, O. (2003). Modified logit life table system: Principles, empirical validation, and application. Population Studies 57(2): 165-182. doi:10.1080/0032472032000097083.

Notestein, F.W. (1945). Population - the long view. In: Schultz, T.W. (ed.) Food for the world. Chicago, USA: University of Chicago Press. 
Oeppen, J. and Vaupel, J.W. (2002). Broken limits to life expectancy. Science 296(5570): 1029-1031. doi:10.1126/science.1069675.

Omran, A.R. (1971). The epidemiologic transition: A theory of the epidemiology of population change. Milbank Memorial Fund quarterly journal 49(4): 509-538. doi: $10.2307 / 3349375$.

Preston, S.H., Heuveline, P., and Guillot, M. (2001). Demography: Measuring and modeling population processes. Malden, Mass: Blackwell Publishers.

Riley, J.C. (2005). The timing and pace of health transitions around the world. Population and Development Review 31(4): 741-764. doi:10.1111/j.1728-4457.2005.00096.x.

Robine, J.M. (2001). Redefining the stages of the epidemiological transition by a study of the dispersion of life spans: The case of France. Population: An English Selection 13(1): 173-194.

Robine, J.M. (2006). Research issues on human longevity. In: Robine, J.M., Crimmins, E., Horiuchi, S., and Yi, Z. (eds.) Human longevity, individual life duration and the growth of the oldest-old population. Netherlands: Springer, International Studies in Population: 7-42.

United Nations (1982). Model life tables for developing countries. New York: United Nations, (sales no. e.81.xiii.7) ed.

United Nations (2008). Social indicators database. New York: United Nations. Http://unstats.un.org/unsd/demographic/products/socind/health.htm (13/01/2008).

Vallin, J. and Meslé, F. (2009). The segmented trend line of highest life expectancies. Population and Development Review 35(1): 159-187. doi:10.1111/j.1728-4457.2009.00264.x.

Vaupel, J.W. and Canudas-Romo, V. (2002). Decomposing demographic change into direct vs. compositional components. Demographic Research 7(1): 1-14. doi:10.4054/DemRes.2002.7.1.

Vaupel, J.W. and Canudas-Romo, V. (2003). Decomposing change in life expectancy: A bouquet of formulas in honor of Nathan Keyfitz's 90th birthday. Demography 40(2): 201-216. doi:10.1353/dem.2003.0018.

Verna, M.K. and Smith, D.P. (1988). The current differential in black and white life expectancy. Demography 25(4): 625-632. doi:10.2307/2061326.

White, K.M. (2002). Longevity advances in high-income countries, 1955-96. Population and Development Review 28(1): 59-76. doi:10.1111/j.1728-4457.2002.00059.x. 
Wilmoth, J.R. (1997). In search of limits. In: Wachter, K.W. and Finch, C.E. (eds.) Between Zeus and the Salmon. The biodemography of longevity. Washington, D.C.: National Academy Press.

Wilmoth, J.R. (2000). Demography of longevity: Past, present and future trends. Experimental Gerontology 35(9-10): 1111-1129. doi:10.1016/S0531-5565(00)00194-7.

Wilmoth, J.R., Canudas-Romo, V., Zureick, S., Inoue, M., and Sawyer, C. (2009). Comparison of the un and who relational mortality models. In: Paper presented at the Population Association of America meeting. Detroit, MI, April 30 - May 2, 2009.

World Health Organization (2008). World health statistics. World Health Organization. Http://www.who.int/whosis/database/core/core_select.cfm (13/01/2008). 


\section{Appendix}

i) Formal proof of relation $2 a$ in the text:

Let the function describing the number of survivors at age $x$ and at time $t$ in a life table be denoted as $\ell(x, t)$. Life expectancy at age $x$ and time $t$ is calculated in terms of the survival function as:

$$
e_{x}(t)=\frac{\int_{x}^{\omega} \ell(a, t) \mathrm{d} a}{\ell(x, t)},
$$

where $\omega$ is the highest age attained by a member of the population. To simplify some of the equations presented below, let the radix of the life table be equal to one, $\ell(0, t)=1$.

The relations in equations 1 and 2 can be derived by noting that life expectancy at birth is a function of the life expectancy at age one. From equation A1 for life expectancy at birth we have:

$$
e_{0}(t)=\int_{1}^{\omega} \ell(x, t) \mathrm{d} a+\int_{0}^{1} \ell(x, t) \mathrm{d} x .
$$

The first term on the right is the product of life expectancy at age one by the number of survivors at age one, the second term is the person-years lived between birth and age one, which represent the two terms of equation 2a in the text:

$$
e_{0}(t)=e_{1}(t)\left[1-{ }_{1} d_{0}(t)\right]+{ }_{1} L_{0}(t) .
$$

ii) Proposal of how to decompose the change over time in the difference in life expectancies

Let $\Delta e_{0-1}(t)=e_{0}(t)-e_{1}(t)$ denote the difference in life expectancies at birth and at age one at time $t$, derived from subtracting $e_{1}$ from equation A3. To disentangle the share of the change that is due to mortality at young ages and the part due to mortality after age one, its change over time is decomposed. The change over time in $\Delta e_{0-1}$ can be studied by calculating its derivative with respect to time (Vaupel and Canudas-Romo 2002; 2003). Let a dot on top of a variable denote the partial derivative with respect to time. Then we find that the change in the difference can be separated as:

$$
\dot{\Delta} e_{0-1}(t)={ }_{1} \dot{L}_{0}-{ }_{1} \dot{d}_{0}(t) e_{1}(t)-{ }_{1} d_{0}(t) \dot{e}_{1}(t) .
$$

The first two terms on the right of equation A4 correspond to changes occurring in the first year of life, while the third component corresponds to changes after age one. 
The number of deaths before age one, ${ }_{1} d_{0}(t)$, has declined over time and the number of person years lived before age one, ${ }_{1} L_{0}(t)$, has increased. As a consequence, the first two components will contribute to the positive increase of the difference. Opposed to this is the overall trend of increase in life expectancy at age one. Therefore, the third component of the change in life expectancy at age one opposes the increase in $\Delta e_{0-1}$. In some periods adult mortality increased, so $e_{1}$ declined. As a consequence the third component in equation $\mathrm{A} 4$ sometimes contributes positively to the increase in $\Delta e_{0-1}$ (for example see Table 2 panel for Russia). In the text we refer to equation A4 as the "Change in $e_{0}-e_{1}$ " explained by "Changes below age one", and by "Changes above age one".

If data are available for two points in time, denoted as $t_{1}$ and $t_{2}$, the relation in equation A4 can be estimated using the decomposition of Kitagawa (1955) as

$$
\dot{\Delta} e_{0-1}(t)=\left({ }_{1} L_{0}^{t_{2}}-{ }_{1} L_{0}^{t_{1}}\right)+\left({ }_{1} d_{0}^{t_{1}}-{ }_{1} d_{0}^{t_{2}}\right)\left[\frac{e_{1}^{t_{1}}+e_{1}^{t_{2}}}{2}\right]+\left(e_{1}^{t_{1}}-e_{1}^{t_{2}}\right)\left[\frac{{ }_{1} d_{0}^{t_{1}}+{ }_{1} d_{0}^{t_{2}}}{2}\right] .
$$

\section{iii) Generalization of the life expectancy crossing}

Crossings between life expectancies at birth and at ages above infancy have also occurred over time. Similar to equation 1 , it is possible to obtain relations between life expectancies at birth and at other older ages. For example, the crossing with life expectancy at age five occurs at the time when the inverse of under five mortality is equal to life expectancy at age five, i.e.

$$
e_{0}=e_{5} \Leftrightarrow \frac{1}{{ }_{5} m_{0}}=e_{5} .
$$

Figure 8 includes the timing of the crossing between $e_{0}$ and $e_{5}$ for the HMD countries with available data and the child mortality level at the time of the crossing. Figure 8 is analogous to timing of the crossing between life expectancies at birth and age one presented in Figure 4. 
Figure 8: $\quad$ Life expectancy at birth at the year of the first crossing with life expectancy at age five, total population by country

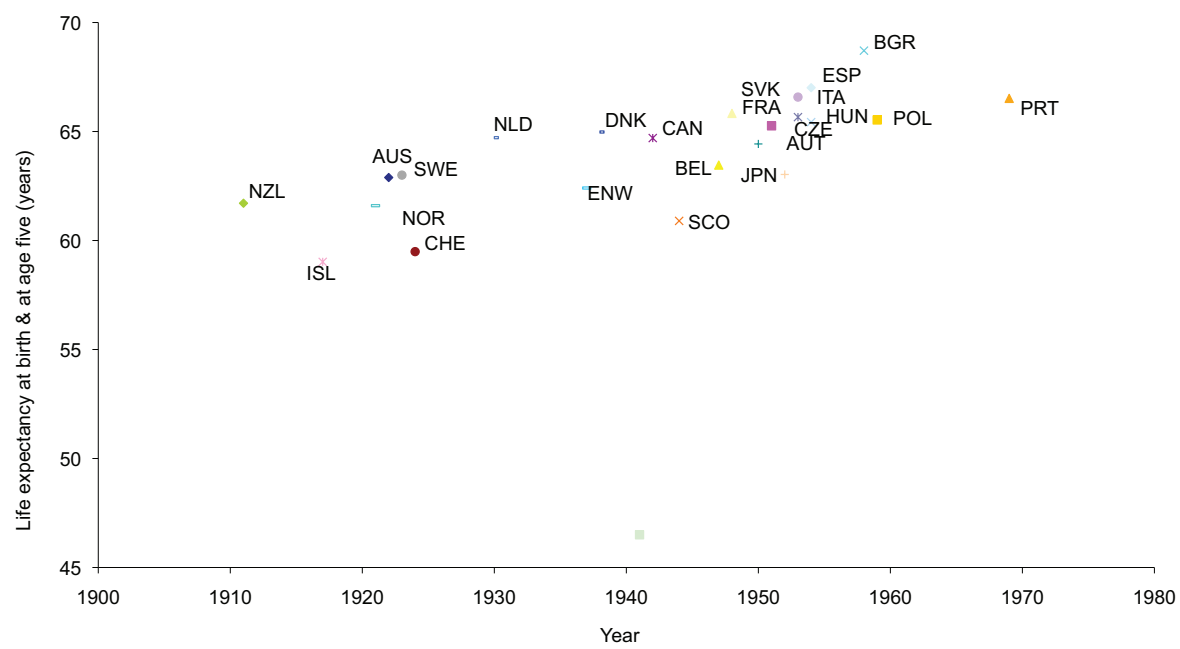

Source: Human Mortality Database (2010). See text for details of countries included. Table 1 has the countries 3-letter codes.

Several countries from the HMD have mortality series that start after the crossing between $e_{0}$ and $e_{5}$. For this reason we left out of Figure 8: Belarus, Chile, Estonia, Germany (ex-GDR and ex-FRG), Northern Ireland, Lithuania, Luxembourg, Latvia, Russia, Slovenia, Taiwan, Ukraine and the USA. The New Zealand (total population) was also taken out for this reason, although the Non-Maori population from this country experienced the crossing in 1911. In Figure 8 it is more difficult to see regional patterns, even though Eastern and Southern Europe achieve the crossing much later than Northern Europe. Portugal is the last to achieve the equality in equation A6 among the countries with available data in the Human Mortality Database (2010). The range of values of life expectancy at the time of the crossing is wider than those observed in Table 1. For the total population, values of life expectancy are found between 46 and 69 years, but the distribution is much wider among males (22 years) than for females (10 years) (not shown). 
Canudas-Romo \& Becker: The imbalance in the life table 